\title{
Dramaturgia de la cotidianidad en la obra de Laura Papo Bohoreta
}

Palabras clave: teatro sefardí, escritura femenina, Bosnia

1

El término dramaturgia en el sentido original y clásico significa el «arte de la composición de obras teatrales» (Pavis, 1990: 155); sin embargo, en tiempos más recientes, la palabra se ha ampliado en sus significados con respecto al original clásico y no deja de crear dificultades para su definición. «En los últimos años se ha dado un fenómeno que ha puesto en jaque a los críticos y teóricos, al mismo tiempo que a los creadores y al público. Se trata de una especie de subgénero híbrido que han querido denominar como narratugia (algunos también lo llaman dramativa), que es una mezcla de los vocablos narrativa y dramaturgia para designar una dramaturgia narrada» (Cantú Toscano, 2012: 1). En este sentido y por las características que presenta la obra dramática de Laura Papo, me ha parecido interesante tomar el término dramaturgia para indicar la lectura que la autora hace de la realidad que la circunda y que traslada al texto y a su vez al escenario, como asimismo el modo en que lo realiza.

¿Por qué una dramaturgia de la cotidianidad? Puede hasta resultar redundante decirlo pero para la autora narrar la cotidianidad en su simplicidad y en sus conflictos se conjuga con una necesidad íntima de expresión. En Bohoreta «se distingue su estilo peculiar: una escritura netamente femenina. Ya en su primera novela puso de manifiesto una asombrosa capacidad de crear personajes femeninos profundos, convincentes, vivos y con un rico mundo interior» (Papo, 2010). Laura remite a los ambientes de la casa y la vida cotidiana de la mujer: cuestiones que atañen a la familia, a los quehaceres domésticos, a las 
dificultades laborales; las mujeres con sus creencias y pensamientos, enfrentando las nuevas situaciones a veces inesperadas. Podemos, a mi parecer, hablar de textos que se acercan a la idea de teatro de lo cotidiano o teatro mínimo, según la definición que da P. Pavis. Se trata de un teatro hiper-realista, vinculado al «naturalismo de la escena y de la actuación: asistimos a acontecimientos, a menudo repetitivos, siempre tomados a ras de la realidad cotidiana y de la subsistencia de cada instante» (Pavis, 1990: 479).

La narración de la cotidianidad, a veces redundante, que la autora produce en sus textos dramáticos, en el pasado ha producido críticas parciales (o negativas) de su obra. Nos detenemos en dos ejemplos: dos comentarios publicados después de la representación de dos de sus dramas. Con respecto a Esterka - Ritrato social de nuestros días en 3 actos del 1930 -la obra más conocida y representada de la autora-, leemos que «los diálogos están lejos de la acción, la autora se distancia de la misma porque esa era su forma de escribir» (Jevrejski Glas, 1930). ${ }^{1}$ Laura Papo divierte con su voz viva y con el humor local, sin embargo según las palabras del autor de la crítica -que firma be.p y que identificamos en Benjamin Pinto (Nezirović, 1992: 555)«las conversaciones, los "entremeses", son divertidos y vivos, a veces tristes y pesados, muchos y variados. De todo ello no se favoreció el drama que duró cinco horas» (Jevrejski Glas, 1930). Por otra parte, notamos que «Ožos mios no posee ninguna virtud que se pueda atribuir a una buena obra dramática [...] no hay acción, no hay conflicto, no hay técnica dramática» (Jevrejski Glas, 1931: 7). Dos críticas seguramente incisivas pero que circunscriben a una única interpretación la lectura de las obras de la autora.

En términos generales podemos decir que existen dos enfoques en el análisis de las obras de Laura Papo. Las mismas resultan ser una fuente rica de información sobre las costumbres, la tradición, el folclor sefardí de Bosnia. K. Vidaković, retomando también algunos artículos del pasado, dice que:

Bohoreta escribió piezas que representaban colages de material folclórico y esto es lo más valioso que representó y representa. El público reconocía en la escena los rostros de su medio, la lengua y cotidianidad, las costumbres de hace siglos, sus raíces en la cultura española de la época de Cervantes (Vidaković, 1990: 107).

M. Nezirović comparte esta lectura pero la amplía considerando que en la obra de nuestra autora existe una dimensión más amplia y universal. Por mi

1 Las traducciones al español de las citas que en original son en serbio, croata, bosnio son de la autora. 
parte, he profundizado los dos enfoques y he intentado encontrar una clave de lectura e interpretación de la forma (criticada) de escribir de la autora a menudo descriptiva, repetitiva, detallista, superflua, etc. pero no, según mi parecer, necesariamente ausente de significado y sí, a menudo, funcional al objeto que se quiere expresar.

Laura Papo ha escrito cuentos y comedias, pero unos y otras ofrecen una maleabilidad genérica que desnuda su naturaleza ambigua. Así como sus cuentos pueden convertirse, casi naturalmente, en cuadros de costumbres o en textos dramáticos aptos a la representación, sus comedias podrían ser objeto de la narración. En sus obras teatrales, además, subyacen con fuerza los elementos, como hemos dicho, de una épica de los hechos cotidianos en los que el relato se convierte en un elemento característico.

Tomo en consideración dos textos de Laura Papo: el primero es el ya mencionado Ožos mios - Pedazo de folklor sefardi de Bosna en 3 aktos (1931) escrito en dos versiones y aún no publicado que, no obstante su formulación dramática, presenta elementos y procedimientos narrativos; el segundo, es Dulce de rosas (1932) un cuento breve con fuertes connotaciones dramáticas. Todo ello para entrar en los espacios contiguos, no sólo culturales, sino también entre los géneros en los que se mueve la autora. Con respecto al texto dramático Ožos mios se trata de un texto teatral que podemos definir tragicómico, en el que los enredos, de carácter muy simple y divertidos y trágicos a la vez, remiten en algunos aspectos a lo burlesco, macabro, lindando con lo absurdo, sin que todo ello conlleve los significados profundos de estos términos, lo cual testimonia la variedad de lecturas a las que la obra puede ser sometida. Ya desde el mismo subtítulo -Pedazo de folklor sefardi de Bosna en 3 aktos-y la ofrenda-Dedicados penserios y membransa a nuestras nonas-, la autora privilegia, de algún modo, una explícita indicación de lectura que, en este caso, puede connotar desde el epigrama hasta otros géneros reflexivos y narrativos. Es un texto en el que la intención narrativa parece predominar más allá de su escritura teatral. Esta intersección obra de manera permanente en la autora. Es un procedimiento que le permite narrar acontecimientos que suceden fuera del campo específico de la escena teatral. Presenta hechos, describe sentimientos, indica intenciones, reflexiona sobre aspectos múltiples de la realidad cotidiana, llega a conclusiones. El punto de partida para construir el drama es el espanto como elemento desencadenante de muchas otras situaciones vividas por los personajes. La obra fue representada y tuvo en su momento la crítica mencionada que nos parece interesante nuevamente traer a colación. Leemos: 
Se trata de una serie de cuadros de la vida sefardí en nuestros territorios y por ello tiene su valor. Resucitó el recuerdo de aquellas habitaciones con minderluk, un extraño y pequeño reloj sobre la pared, ante nosotros volvieron a caminar y a hablar nuestras abuelas y abuelos muertos que tanto nos querían. La señora Laura mostró una capacidad de observación fina, una aptitud rara de juntar y ofrecer las cosas de manera tan perfecta, real, completa como fueron de verdad. De manera óptima fue representada su forma de vivir patriarcal, su filosofía de vida, su forma de hablar. Con su talento natural para el humor tejió los diálogos con diversión y con chistes y logró que los espectadores rieran sinceramente (Jevrejski Glas, 1931: 7).

Son precisamente estos procedimientos y esta interlocución con el público los que constituyen un aspecto central de la representación escénica. La crítica sin embargo concluye con esta objeción: «Con pinceladas más breves, con diálogos más concisos se hubiera podido decir tan bien lo mismo» (Jevrejski Glas, 1931: 7). Es en esta última objeción donde encontramos una diferencia de no poco valor con respecto a algunos conceptos hoy claramente delimitados por la teoría del espectáculo, como es la idea, por ejemplo del texto espectacular. El texto, en cuanto tal, puede ser objeto estético de una lectura, pero, al ser representado debe manejarse con los recursos propios del texto espectacular. Ahora bien, en algunos autores, la inmediatez expresiva hace que las diferencias entre el texto dramático y el espectacular coincidan, como creemos puede ser el caso de Laura, y los efectos que pretenden lograr están ya inscriptos en el mismo texto de partida.

En esta crítica y valoración de su obra, intervienen los cánones rígidos de la época y, sobre todo, del mundo cultural en que Laura Papo ejerce su vocación. En un contexto en que los valores estéticos predominan, desconocer las reglas, adrede o no, más que una audacia creativa, puede parecer una falta de dominio de los mecanismos en boga acerca de la creación más que la elaboración lúcida de una realidad que reclama, en términos de arte, una escritura como la que cultiva nuestra autora. Sus textos obedecen a una necesidad de expresión que hace de la escritura un instrumento con claras connotaciones orales. La inmediatez expresiva de que Laura Papo hace gala es deliberada. De ahí que las críticas a sus dramas y puestas en escena, hechas desde una perspectiva tradicional, reflejan, de algún modo, la impotencia de esta perspectiva para acceder a una escritura que reclama otros enfoques para su análisis. 
Una de las temáticas más presentes en la obra de Laura Papo es la constante referencia a la tradición, al recuerdo del pasado, a través de la confrontación entre las generaciones; los ancianos son siempre quienes preservan la tradición y la transmiten con sabiduría a los jóvenes. El tema lo encontramos en Linda - Rikordo de Oriente (1928) donde un padre y su hija asumen posiciones divergentes frente al modo de realizar el culto; el padre, rabino duda del hecho que se introduzca el órgano en la sinagoga, pero al fin, después de haber subrayado los valores del pasado, acepta. Lo encontramos en Morena (1924 y 1925), cuando el padre asombrado recibe la noticia que su hija se va a casar sin haberlo ni siquiera consultado anteriormente; también en Esterka, donde resulta evidente la distancia generacional entre la abuela y las nietas sumergidas en los cambios de la modernidad. Hay siempre una suerte de reproche por parte de los ancianos sobre todo hacia la mujer, hacia las školadas, por su excesiva tendencia a la adquisición de modos emancipados; sin embargo, la autora trata la temática de manera condescendiente, con una mirada benévola en que el anciano se convierte en una fuente de enseñanzas. En Esterka leemos esta frase: «Ves Linda, esto te es la pedagogia entera en dos palavras, kuantos livros se gastan, i al kavo venimos a loke dizen los viežos!». Lejos de ser planteado como un conflicto insoluble, Laura trata esta temática a menudo con delicadeza y humor, hasta con cierta indulgencia y docilidad, sin que ello quite la determinación y convicción de las posturas juveniles. Es un tema que adquiere características didácticas y en el cual emergen con claridad algunos valores éticos que remiten a prácticas de la vida cotidiana. Más que las rebeldías y la obstinación de las posiciones, aparecen la reflexión y la necesidad de comprensión por parte de unos y otros. Subyace una especie de subtexto, la necesidad de contar, de hacer revivir, de no olvidar su tradición sefardí de Bosnia que lentamente estaba desapareciendo.

\section{2}

En el Deuteronomio² (32; 7), leemos:

Acuérdate de los días de antaño;

de todas las generaciones cuenta los años.

Pregunta a tu padre, y él te lo dirá;

a tus ancianos, y ellos te contarán.

2 El colega Ottavio Di Grazia, estudioso del hebraísmo y profesor en la Universidad Suor Orsola Benincasa de Nápoles, que he tenido la oportunidad de entrevistar, ha contribuido al análisis que aquí propongo. Las citas a continuación pertenecen a un ensayo en elaboración que será publicado próximamente y que gentilmente me ha autorizado a citar. 
Interpretando estos versos, Ottavio Di Grazia hace notar que: «Il concetto di ricordare trova il suo complemento in quello di segno opposto: dimenticare. Al popolo ebraico viene ingiunto di ricordare e al tempo stesso di non dimenticare». Di Grazia afirma que:

la memoria, custodita di generazione in generazione è l'antidoto più potente contro la morte, $[. .$.$] il passato non è qualcosa di$ sorpassato, privo di utilità, ma al contrario costituisce un valido aiuto per affrontare la vita. [...] la Toràh ci induce a renderci conto che possiamo imparare molto dai nostri genitori e che persino i nostri nonni hanno ancora molto da insegnarci.

Estas palabras vienen a propósito de la poética, del proyecto literario de Laura Papo. Recordar el pasado, aunque sea de forma reiterativa (y que a veces pueda dar la impresión de insignificante) implica no solo incidir en los eventos del presente, sino concordar una simbiosis con los mismos.

Il ricordare, però, non si limita a un semplice rievocare un evento passato, poiché la catena della trasmissione del ricordo (di generazione in generazione) non solo custodisce l'evento stesso, ma lo riattiva in forma potenziata, lo restituisce ad una nuova vita nel momento in cui viene rimesso nel circolo della narrazione e della celebrazione.

Al respecto podemos confrontar algunas afirmaciones de Bohoreta en La mužer sefardi de Bosna en el capítulo dedicado a "Fiestas del anjo - diviertimientos de invierno - enverano - Noće de Šabat", donde remite a las costumbres del pasado pero actualizándolas y lamentando la extinción de la tradición. Escribe:

Nuestras nonas i madres, supieron sin ke se dieran kuento, ermozear enšalšar la fiesta kon sus personas, kon sus instinkto estetiko de mužer! El šabat se asperava kada semana komo si era algo nuevo, i siempre alegrava a la famija žudia akeas 24 oras mientres kualas era el balabay rey en su kaza (sigun Heine). (Nezirović, 2005: 136).

Continúa con una descripción de los preparativos de la familia y de la casa: la limpieza, la higiene personal, los vestidos, la comida hasta el momento del kiddush y observa:

Akea paz akel contentes entre las kuatro paredes de su kaza, puedemos afirmar ke otro puevlo no konose! Ni pueden 
azerse una čika idea de la quietud moral de ansina una nočada. Despues del kiduš el bezar la mano de las criaturas a los ženitores, la sena mežor ke kada noće i la korona de entera esta disposición solemne de fiesta era sin dubio el kantar: El Dio dišo ke bueno era/mundo ke uviera. Y duspues se kantava esta otra kantika: Ken guarda el šabat/El Dio lo guarda a el/Para siempre i siempre/E Dio lo guarda a el. (Nezirović, 2005: 138)

Di Grazia subraya que la tarea de transformar el recuerdo en memoria viva y transmitirlo a las generaciones futuras, en el hebraísmo se encuentra en la tradición oral que, en vez de encontrarse aislada y decontextualizada en un monumento, la misma se colocada en la continuidad de un sistema cultural. Podemos, pues, entrever en esta manera dilatada, repetitiva, a veces aparentemente superflua y pesada de la escritura de Laura Papo, la necesidad de fijar el discurso oral, y este fijar la oralidad tiene un significado más profundo que va más allá del simple acontecimiento cotidiano. La estructura interna de las obras de Bohoreta, así como su modo de expresión, a un nivel profundo, tienen una impronta oral ante todo, y luego, por una parte, teatral y, por otra, narrativa, y entre ellas se interfieren. Esta interferencia tiene su razón de ser porque responde funcionalmente a lo que se quiere expresar.

Por otra parte, tanto sus obras teatrales, cuanto sus textos narrativos, no están exentos, en muchos momentos, de un toque de poeticidad simple, cotidiana. Esta funcionalidad de la escritura de Laura Papo nos lleva a pensar en conceptos como los de ruptura, por un lado, y normativa, por otro, y sus méritos y deméritos en el tiempo. Existen en la historia de la literatura numerosos ejemplos en que los cánones de una época desmerecen valores que, a la luz de otros cánones y, obviamente de otras épocas, pueden convertirse en virtudes. Uno de estos cánones era el respeto y la estricta rigidez de los géneros literarios que, sin embargo, más tarde darían lugar a la contaminación genérica, que lejos de constituir un defecto se convertiría en una apertura a las nuevas exigencias del arte y de la realidad. Aquí se entrelazan, de una parte, la necesidad de expresión y, de otra, los recursos aptos para satisfacer esa necesidad de expresión. En una literatura de fuerte proyección semántica, los recursos, tradicionales o no, deben someterse a dicha proyección. Es cuanto hace, deliberadamente o no, Laura Papo. Su declaración de que no le interesa la forma es equívoca, en cuanto esa forma que dice no interesarle adquiere una eficacia textual y contextual. Es, en este sentido, que hablamos de funcionalidad en la escritura de Laura Papo, funcionalidad en el co-texto, es decir en las relaciones 
internas de la escritura, y funcionalidad en el con-texto, es decir en las relaciones del texto con el mundo exterior, público, etc.

Sanchis Sinisterra (2003) en el intento de recuperar la función narrativa del teatro, el equilibrio entre la fábula y el discurso, cuando formula los tres modelos de dramaturgia de textos narrativos, (dramaturgia fabular, discursiva, mixta) subraya como elemento fundamental, para la puesta en práctica de los mismos, el grado de teatralidad latente que reside en cada texto narrativo. El otro ejemplo mencionado al comienzo, Dulce de rosas, puede ser leído e interpretado ¿y por qué no representado? como texto dramático, en particular por los diálogos que lo caracterizan y por la intensidad dramática que la autora transmite en los dos personajes principales del relato: la madre y la hija que ha dado a luz su hijo muerto. Nos hallamos ante un cuento/relato/texto narrativo con una fuerte teatralidad. Las posibilidades dramáticas de este texto no requieren una escenificación forzada, ni una "estilización", sino que subyacen en su misma naturaleza teatral. El «espesor de signos y de sensaciones que se construye en la escena a partir del argumento escrito, esa especie de percepción ecuménica de artificios sensuales, gestos, tonos, distancias, sustancias, luces que sumerge al texto en la plenitud de su lenguaje exterior» (Pavis, 1990: 468), que son los elementos que Barthes enuncia como característicos de la teatralidad, califican su texto.

En Bohoreta, en fin, no encontramos un trasvase de la narrativa al teatro o viceversa; sino que el relato subyace a su forma de concebir y escribir el texto teatral. Autora prolífica, no se detiene en la elaboración y tanto menos en la teorización de lo que escribe. Su poética no se deja atrapar por las obediencias formales en el teatro que seguramente conocía. La intención de Laura Papo coincidía, en muchos aspectos, con la de un narrador, pero acudía a la forma dramática por su funcionalidad como representación. Sus procedimientos teatrales estaban en directa relación con los fines que se proponía: comunicar sus pensamientos «educar a su pueblo» como ella misma ha escrito. La adecuación a estos propósitos, a través de un lenguaje y recursos de inmediata repercusión, constituye y legitima su poética.

\section{Bibliografía}

Cantú Toscano, M. (2012): «La dramaturgia de la dramaturgia. Una aproximación desde las ciencias de la complejidad»: http://es.scribd.com/doc/92927167/ La-dramaturgia-de-la-dramaturgia-Mario-Cantu-Toscano (junio 2014). 
Be. P. (1930): «"Esterka” od gdje Laure Papo, Predstava "Matatje” u Narodnom Pozorištu». En: Jevrejski Glas, 40, 10 de octubre.

Nezirović, M., editor y traductor (2005): Laura Papo Bohoreta, Sefardska žena u Bosni - La mužer sefardi de Bosna, Sarajevo, Connectum.

Nezirović, M. (1992): Jevrejsko španjolska književnost. Sarajevo: Svjetlost.

Papo, E. (2010): «Entre la modernidad y la tradición, el feminismo y la patriarquia: Vida y obra de Laura Papo 'Bohoreta', primera dramaturga en lengua judeo-española», En: Neue Romania, 40, 97-117: http://es.scribd. $\mathrm{com} / \mathrm{doc} / 60281699 /$ Eliezer-Papo-Entre-la-modernidad-y-la-tradicion-elfeminismo-y-la-patriarquia-Vida-yobra-de-Laura-Papo-Bohore (11-2012)

Papo, L. (1924-1925): Morena. En: Jevrejski život 35, 2; 38, 3; 41, 3; 44,5; 46, 3; 48,$3 ; 51,2-3 ; 52,3$.

Papo, L. (1928): Linda-Rikordo de Orijente. En Jevrejski glas, 19, 4.

Papo, L. (1932): Dulse de rozas. En: Jevrejski glas 31, 2-3.

Papo, L. (1931): Ožos mios. Pedazo de folklor sefardi de Bosna en 3 aktos, manuscrito no publicado.

Pavis, P. (1990): Diccionario del teatro. Dramaturgia, estética, semiología. Buenos Aires: Paidós.

Prenz Kopušar, A. C., editora (2012): Esterka de Laura Papo Boboreta: drama en tres actos en judeoespañol de la comunidad sefardí de Bosnia. La Plata: Biblioteca Orbis Tertius, Universidad Nacional de La Plata y Archivo Histórico de Sarajevo.

Prenz, A. C. (2006): Da Sefarad a Sarajevo. Percorsi interculturali: le multiformi identità e lo spazio dell'Altro. Napoli: Esselibri, Collana Beth.

S.n. (1931): Jevrejski Glas, 41, 9 de octubre, 7. En Čampara, E. (1965-1967): «Prilog bibliografiji književnog rada Laure Papo / Bohoreta "Laura Papo Bohoreta"». Beograd: Jevrejski almanah, 136-144.

Sanchis Sinisterra, J. (2003): Dramaturgia de los textos narrativos. Ciudad Real: Ñaque editora.

Vidaković, K. (1990): Kultura španskib Jevreja na jugoslovenskom tlu. Sarajevo: Svjetlost. 


\section{Ana Cecilia Prenz Kopušar}

Università degli Studi di Trieste

\section{Dramaturgy of everyday life in Laura Papo Bohoreta's writings}

Keywords: Sephardic theatre, women's writing, Bosnia

This paper aims to analyse some dramatic and theatrical features of the Bosnian Sephardic author, Laura Papo Bohoreta (Sarajevo 1891-1942). Her wide dramatic and literary production was written in Judeo-Spanish between the two wars. In particular, the dramatic text Ožos mios, Pedazo de folklor sefardi de Bosna en tres actos (1931) and some of her short stories are considered. The strong narrative connotation of Laura Papo's plays and the strong theatricality typical of her short stories are also discussed. It can be said that Laura Papo has dealt equally with both genres because her plays and her short stories alike reveal an ambiguous and adaptable nature. In fact, her stories can easily become plays that can be performed in the theatre, while at the same time her plays can turn into narratives. An epic of daily life also emerges in her plays. Laura Papo's vision of women, the generation gap as a theme of her stories and plays and, finally, her relationship with the tradition are shown. 


\section{Ana Cecilia Prenz Kopušar}

Univerza $v$ Trstu

\section{Dramaturgija vsakdanjosti v delih Laure Papo Bohoreta}

Ključne besede: sefardsko gledališče, ženska pisava, Bosna

Prispevek analizira nekatere narativne in dramaturške vidike, značilne za dela sefardske avtorice iz Bosne, Laure Papo Bohoreta (Sarajevo, 1891-1942). Njeno bogato dramsko in literarno delo, nastalo $\mathrm{v}$ letih med obema svetovnima vojnama, je napisano v judovski španščini. Prispevek posveča pozornost zlasti drami Ožos mios, Pedazo de folklor sefardi de Bosna en tres actos (1931) in nekaterim kratkim zgodbam. Poudarja močno narativno konotacijo, značilno za dramska dela Laure Papo, in močno gledališkost, prisotno v njenih kratkih zgodbah. Laura Papo se dotika obeh žanrov, kajti v njenih dramah in kratkih zgodbah se odražata obe literarni vrsti. Tako kot se lahko njene kratke zgodbe preobličijo, skoraj povsem naravno, v cuadros de costumbre (zgodbe o vsakdanjem življenju) ali v dramska besedila, primerna za uprizoritev, so lahko njena gledališka dela predmet naracije. Poleg tega so v njih močno prisotni elementi epike vsakdanjih dogodkov, v katerih postane pripoved njihova bistvena značilnost. Avtorica v prispevku razpravlja še o pogledu ženske in o generacijski distanci, o katerih pisateljica premišljuje v svojih kratkih zgodbah in dramskih delih, pa tudi o njenem odnosu do tradicije. 